\title{
Influence of neighborhood size and exposure duration on visual-word recognition: Evidence with the yes/no and the go/no-go lexical decision tasks
}

\author{
MANUEL PEREA and EVA ROSA \\ Universitat de València, València, Spain \\ and \\ CONSOLACIÓN GÓMEZ \\ Universitat Jaume I, Castelló, Spain
}

\begin{abstract}
We present two experiments in which we measured lexical decision latencies and errors to words with few or many orthographic neighbors (i.e., Coltheart's $N$ ). The main goal of the study was to examine whether or not the neighborhood size effect in a lexical decision task could be affected by the exposure duration of the stimulus item (unlimited vs. limited time exposure, $150 \mathrm{msec}$ plus a backward mask) and the type of decision involved in the task (yes/no vs. go/no-go lexical decision tasks). In the yes/no task, the results showed a facilitative neighborhood size effect for low frequency that did not interact with exposure duration (Experiment 1). In contrast, in the go/no-go task (in this task, participants are instructed to respond as quickly as they can when a word is presented and not to respond if a nonword is presented), the neighborhood size effect for low-frequency words (and for nonwords) was greater under limited viewing time (Experiment 2). In addition, the word frequency effect was greater in the go/no-go task than in the yes/no task, replicating Hino and Lupker $(1998,2000)$. The results were interpreted in terms of the interaction of decision and lexical factors in visual-word recognition.
\end{abstract}

One of the most important issues in the literature on visual-word recognition is the exploration of the effects of orthographic neighborhood structure on performance in reading and word identification tasks. In this context, most researchers currently agree that, upon the visual presentation of a word (e.g., horse), similarly spelled words (the so-called orthographicneighbors, e.g., worse, gorse, house, or horde) become partially activated and affect the speed of lexical access (for a review see Andrews, 1997; Grainger \& Jacobs, 1996; Pollatsek, Perea, \& Binder, 1999). Coltheart, Davelaar, Jonasson, and Besner's (1977) definition of an orthographic neighbor (i.e., any word that can be created by changing one letter of the stimulus item, preserving letter positions) has been adopted by virtually all researchers in this field to date. This is why the neighborhood

Parts of this research were reported at the 35th Australian Experimental Psychology Conference, Melbourne, 2001. The first author was supported by a grant from the Secretaría de Estado de Educación y Universidades of Spain. E. R. and C. G. were the recipients of a predoctoral grant from the Spanish Ministry of Science and Culture. We thank Daniel Zagar, Susan Lima, and an anonymous reviewer for very valuable comments and criticism on earlier versions of the paper. We also thank Isabel Fernández for help in the final version of the paper. Correspondence concerning this paper should be sent to M. Perea, Departament de Metodologia, Facultat de Psicologia, Av. Blasco Ibáñez, 21, 46010València, Spain (e-mail: mperea@uv.es). of a word has been defined as the set of neighbors of that word (or Coltheart's $N$ ).

Previous research has found a facilitative effect of $N$ (or neighborhoodsize) on words in lexical decision and naming, although the effect seems to be restricted to lowfrequency words (see Andrews, 1997). This finding seems to raise problems for the theoretical accounts based on the principle of lateral inhibition at the lexical level, such as the interactive activation (IA) model (McClelland \& Rumelhart, 1981; see Jacobs \& Grainger, 1992, and Perea $\&$ Rosa, 2000, for failures to simulate the effect of $N$ with this model). ${ }^{1}$ The facilitative effect of $N$ is also damaging for any models based on a frequency-based serial search across the set of candidates - for example, the activationverification (AV) model (Paap, Newsome, McDonald, \& Schvaneveldt, 1982) and the search model (Forster, 1976). Nonetheless, it has been argued that these facilitative effects of $N$ in the lexical decision task are not necessarily genuine (i.e., they are not indexing the speed of lexical access) but, instead, may be reflections of a different, taskspecific process (see Andrews \& Heathcote, 2001; Coltheart, Rastle, Perry, Langdon, \& Ziegler, 2001; Forster \& Shen, 1996; Grainger \& Jacobs, 1996; Paap \& Johansen, 1994; Pollatsek et al., 1999). Specifically, if we assume that the presence of many neighbors produces increased general excitation in the internal lexicon and that this excitation helps to bias the response in the lexical decision task to 
yes, then we would expect that yes decisions to words with many neighbors would be facilitated but that no decisions to nonwords with many neighbors would be inhibited, as actually occurs (for a demonstration of these effects, see Andrews, 1989, 1992; Carreiras, Perea, \& Grainger, 1997b; Forster \& Shen, 1996; Perea \& Rosa, 2000; Sears, Hino, \& Lupker, 1995). Keep in mind that the lexical decision task is a word/nonword discrimination task and, because of low levels of lexical activation in the early stages of word processing, low-frequency low- $N$ words (e.g., havoc) may require some additional processing time to produce a $y e s$ response, relative to high- $N$ words of similar frequency (e.g., bland).

Further evidence supporting the contamination by a decision-biasing effect on the facilitative effect of $N$ in the lexical decision task is that this effect is substantially weaker when the nonword distractors closely resemble a word (Andrews, 1992; Carreiras et al., 1997b; Grainger \& Jacobs, 1996) and when accuracy is stressed over speed in the instructions (Grainger \& Jacobs, 1996). Consistent with this explanation, data from several eye movement studies suggest that $N$ has an inhibitory influence (if anything) in the processing of a target word in normal (silent) reading (Pollatsek et al., 1999); interestingly, these same words show a facilitative effect of $N$ in the lexical decision task. Finally, it is worth noting that the fact that the effect of $N$ is typically facilitative in word naming (see Andrews, 1997) does not imply that the effect has a lexical basis. A facilitative effect of $N$ in the naming task can be explained in terms of phonologicalor articulatory processes specific to this task, such as the degree of consistency of the pronunciation of the orthographic rime (see, e.g., Grainger, 1992; Jared, McRae, \& Seidenberg, 1990; Perea \& Carreiras, 1998; Treiman, Mullennix, Bijeljac-Babic, \& Richmond-Welty, 1995). In fact, neighborhood size effects in naming are similar for low-frequency words and pseudowords (e.g., Peereman \& Content, 1995; Perea \& Carreiras, 1996), which also suggests that nonlexical factors play a role in the effect of $N$ in the naming task.

Grainger and Jacobs (1996; Jacobs, Rey, Ziegler, \& Grainger, 1998) proposed an extension of the IA modelthe multiple read-out model (MROM) - that incorporates the possibility of making lexical decisions not only on the basis of unique word identification (the $M$ criterion, as in the original IA model; see McClelland \& Rumelhart, 1981), but also on the basis of incomplete processing of the stimulus (i.e., on the basis of summed lexical activity: the $\Sigma$ criterion). The dual-route cascaded (DRC) model (Coltheart et al., 2001) and the AV model (Paap \& Johansen, 1994) can also produce "fast guesses" as a function of global lexical activity in a lexical decision task; however, for simplicity's sake, we will focus on the MROM. The latency of a yes response in the MROM depends on which criterion $(M$ or $\Sigma)$ is reached first. Interestingly, if a given stimulus generates lexical activity that lies above certain critical values in the early stages of processing (i.e., if the item is wordlike), the $\Sigma$ criterion is consequently lowered (Grainger \& Jacobs, 1996). In this way, low-frequency high-
$N$ words (but not low-frequency low- $N$ words) can give rise to fast positive responses generated by the criterion. Nonetheless, if responses are made via unique word identification, the MROM predicts an inhibitory effect of having at least one higher frequency neighbor; this is the neighborhoodfrequency effect (Grainger \& Jacobs, 1996; Grainger, O’Regan, Jacobs, \& Segui, 1989, 1992; see, also, Carreiras et al., 1997b; Grainger \& Segui, 1990; Huntsman \& Lima, 1996; Perea \& Pollatsek, 1998; Zagar \& Mathey, 2000; but see Forster \& Shen, 1996, and Sears et al., 1995 , for failures to obtain the effect). ${ }^{2}$

The MROM explains the increase in facilitative effects of $N$ on correct reaction times (RTs) to word stimuli as the result of increased use of the $\Sigma$ criterion, as compared with the $M$ criterion. The model also captures the interaction between word frequency and neighborhood size: High-frequency words reach the $M$ criterion more rapidly than do low-frequency words and, therefore, leave less opportunity for the $\Sigma$ criterion to intervene (Grainger \& Jacobs, 1996). With respect to lexical decision responses on nonword stimuli, Grainger and Jacobs indicated that participants set a time limit (the $T$ criterion) that is adjusted on each trial as a function of global lexical activation (see Coltheart et al., 1977, for a similar proposal). When the $M$ or the $\Sigma$ criterion is not reached before the $T$ criterion, participants make a no decision. As occurs with the $\Sigma$ criterion, if a given stimulus generates lexical activity that lies below certain critical values in the early stages of word processing, the $T$ criterion is lowered. In this way, the model captures the inhibitory effect of $N$ with nonwords in the latency data. As such, the MROM accounts for a large number of findings in the visual-word recognition literature (see Grainger \& Jacobs, 1996; Jacobs et al., 1998).

In the present experiments, we reexamined the neighborhood size effect, using a relatively large set of items per condition (64 items per neighborhood condition). These materials were held constant across a series of within-item manipulations (i.e., each word was compared with itself): stimulus presentation duration of the stimulus (items were presented either briefly/masked or until the participant's response) and type of response (yes/no lexical decision task or go/no-go lexical decision task). As Forster (2000) pointed out, this type of within-item design overcomes one of the critical problems in psycholinguistic research: the potential contamination from uncontrolled variables that may occur when items are selected in a word recognition experiment. In addition, to reexamine whether or not the effect of neighborhood size affects only low-frequency words (Andrews, 1989, 1992), we also manipulated word frequency (overall, there were 32 words in each of the neighborhood-size-word-frequency conditions). It is worth noting that different languages may have a different sensitivity to the effects of neighborhood size (see Andrews, Content, \& Peereman, 2000; Carreiras et al., 1997b; Ziegler \& Perry, 1998). For instance, it has been suggested that orthographic neighborhood effects tend be facilitative in English because of the dominant role of body neighbors in this language (i.e., words that share the 
same orthographic rime; see Ziegler \& Perry, 1998). However, in Spanish, the effect of $N$ for words tends to be less robust than the reported effect of $N$ with English words (e.g., Carreiras et al., 1997b).

\section{Stimulus Presentation Duration and the Neighborhood Size Effect}

The rationale for the manipulation of stimulus presentation duration in the present study is that Grainger et al. (1992) found that the neighborhood frequency effect was dramatically reduced when the stimulus presentation duration was limited to $160 \mathrm{msec}$ (followed by a pattern mask), as compared with when the stimuli remained on the computer screen until the participant responded (12 vs. $48 \mathrm{msec}$, respectively). How can the MROM accommodate these results? The only possibility is to assume that participants relied on the $\Sigma$ criterion more frequently in the limited viewing time condition. (We should note that Grainger and Jacobs did not simulate Grainger et al.'s, 1992, study in their 1996 paper, though.) Keep in mind that the $M$ criterion in the MROM is a fixed property of the word recognition system (i.e., it is not strategically modifiable). Since word recognition has been hindered in the limited viewing time condition (because of the brief stimulus presentation duration and the pattern mask), participants might have relied on incomplete processing of the stimuli ( $\Sigma$ criterion), rather than on unique word identification, to make the lexical decision responses. Use of the $\Sigma$ criterion would decrease the magnitude of the neighborhood frequency effect. (Note that this reasoning also implies that the neighborhood size effect would be greater under limited viewing time.) Consistent with this explanation, the mean RT for the unlimited viewing time experiment was $656 \mathrm{msec}$ (Experiment 1, with a 12-msec neighborhood frequency effect), whereas it was only $598 \mathrm{msec}$ for the limited viewing time experiment (Experiment 2; with a 48 -msec neighborhood frequency effect). ${ }^{3}$

Given that the manipulation in Grainger et al.'s (1992) experiments was between subjects, the issue is whether the participants in Experiment 2 were simply faster than those in Experiment 1 and, so, the neighborhood frequency effect decreased (i.e., the participants were relying on incomplete processing of the stimulus) or, alternatively, whether it was the manipulation of stimulus presentation duration that caused the decrease in the magnitude of the neighborhood frequency effect. Keep in mind that the use of brief and masked presentations does not necessarily provoke faster RTs (e.g., Allen, McNeal, \& Kvak, 1992; Perea, Rosa, \& Gómez, 2002a). To avoid any potential strategies that participants could use when the stimulus presentation duration was blocked across participants, the manipulation of the stimulus presentation duration was within subjects in the present experiments. Alternatively, we should note that the small neighborhood frequency effect in the limited viewing time condition in Grainger et al.'s (1992) study could also be explained if one assumes that participants can correctly respond yes to the stimulus item on the basis of incorrect retrieval of a more frequent (ac- tivated) neighbor in the limited viewing time condition (for similar reasoning, see Andrews, 1996; Coltheart et al., 2001; Pollatsek et al., 1999). In either case, the two accounts predict that the neighborhood size effect for lowfrequency words should be greater in the limited viewing time condition than in the unlimited viewing time condition. (In fairness to Grainger et al., 1992, we should indicate that the main goal of their study was not to compare unmasked vs. masked performance but to examine whether varying the fixation position in the stimulus word could produce variations in the neighborhood frequency effect.)

With respect to the nonword stimuli, the inhibitory effect of neighborhood size should be greater under limited viewing time, since the high degree of activation from high- $N$ nonwords may provoke a number of false positive responses (see above). (Grainger et al., 1992, did not report the nonword data, though.) In other words, when the stimuli are presented for limited viewing time (and are subsequently masked), the opportunity for misperceptions increases. Consistent with this prediction, Perea et al. (2002a) found that, when the items were presented briefly $(150 \mathrm{msec})$ and subsequently masked, participants made more errors to nonwords created by changing a letter from a high-frequency word than to nonwords created by changing a letter from a low-frequency word $(18.5 \%$ vs. $10.5 \%$, respectively). Interestingly, this effect did not occur when the items were presented until the participant's response ( $4.7 \%$ vs. $6.9 \%$, respectively).

In sum, items in the limited viewing time condition were presented for $150 \mathrm{msec}$ and were immediately replaced by a pattern mask (a row of number signs), whereas items in the unlimited viewing time condition were presented until the participant's response. As Grainger et al. (1992) pointed out, a stimulus presentation duration of around $150 \mathrm{msec}$ allows only one eye fixation on the stimulus item, which maximizes the chances for misperceptions, relative to the unlimited viewing time condition.

\section{The Yes/No and the Go/No-Go Lexical Decision Tasks}

An additional goal of the present study was to examine whether or not the neighborhood size effect would be affected by the type of decision involved in the lexical decision task: the standard yes/no task versus the go/no-go task. In the go/no-go task, participants are instructed to respond as quickly as they can when a word is presented and not to respond if a nonword is presented. The go/no-go procedure applied to the lexical decision task is becoming increasingly popular as a complement or replacement of the standard yes/no procedure (for some recent examples, see Davis, Castles, \& Iakovidis, 1998; Gibbs \& Van Orden, 1998; Hino \& Lupker, 1998, 2000; Perea \& Rosa, in press; Perea, Rosa, \& Gómez, 2002b). In this light, Grainger and Jacobs (1996) indicated that future tests of the MROM should include the go/no-go task, since this task represents an intermediate case between a speeded identification task (which relies only on unique word identification: the $M$ criterion) and the standard yes/no lexical decision task 
(which relies on the $M$ and the $\Sigma$ criteria for $y e s$ responses and on the $T$ criterion for $n o$ responses). In the MROM, the go/no-go task would use only two response criteria (the $M$ and $\Sigma$ criteria; i.e., participants cannot say no).

It is worth noting that Gordon (1983; see, also, Peressotti \& Grainger, 1995) suggested that the go/no-go lexical decision task might provide less noisy data than the yes/no task. The argument is that by minimizing part of the response selection process in the experimental task, the impact of response decision time on the obtained lexical decision time in the go/no-go task would be reduced (relative to the standard yes/no task), thereby reducing subsequent variability. However, Gordon (1983; Gordon \& Caramazza, 1982; Peressotti \& Grainger, 1995) did not report data that could be used to assess this claim. Finally, it may be of interest to mention that the go/no-go task seems to offer more accurate responding, faster RTs, and fewer processing resources than the yes/no task (Perea et al., 2002a). Furthermore, the go/no-go task may also provide "more time for word dynamics to run toward coherent states" (Gibbs \& Van Orden, 1998, p. 1180), given that nonwords do not require an overt response. As a result, is has been suggested that the go/no-go task could be an excellent alternative to the standard yes/no task (Gordon, 1983; Perea et al., 2002b; Yelland, 1993).

Although one might argue that the yes/no and the go/nogo tasks probably reflect the same underlying processes for a yes response (e.g., Grainger \& Jacobs, 1996), recent research has shown some conflicting results with respect to the role of such factors as word-frequency in these two tasks (Hino \& Lupker, 1998, 2000; Perea et al., 2002b). Hino and Lupker $(1998,2000)$ found that the word frequency effect was larger in the go/no-go task than in the yes/no task and suggested that the two tasks could involve different demands. In the yes/no task, there is pressure to make a rapid response to all stimuli (words and nonwords). When an unfamiliar low-frequency word is encountered, participants might make the wrong answer, and these trials would end up counting as errors, not contributing to the mean latency for low-frequency words. In contrast, in the go/no-go task, a trial-terminating negative response would not be made, since nonwords do not require a response, and lexical processing would continue. In this case, the participant may make a slow response (assuming that the word is in the participant's vocabulary), and these responses would increase the mean RT for low-frequency words, thereby increasing the magnitude of the word frequency effect (see Hino \& Lupker, 1998).

However, in several experiments in our lab, we have found a similar word frequency effect with the two tasks (Perea, Fernández, \& Carreiras, 1998; Perea et al., 2002b; see, also, Gordon \& Caramazza, 1982). We do not know the exact reason for this discrepancy. In Perea et al.'s (1998; Perea et al., 2002b) experiments, the percentage of nonword errors was quite similar for the go/no-go task and the yes/no task. In contrast, the percentage of nonword errors in Hino and Lupker's $(1998,2000)$ experiments was consistently higher for the yes/no task, which suggests that participants may have used different criterion settings in the two varieties of the lexical decision task. In sum, to test the role of the type of lexical decision on the magnitude of the neighborhood size effect (and the word frequency effect), in Experiment 1 we used the yes/no lexical decision task, whereas in Experiment 2 we used the go/no-go lexical decision task.

\section{EXPERIMENT 1 Yes/No Lexical Decision Task}

\section{Method}

Participants. Twenty-four psychology students from the University of València took part in the experiment for course credit. All of them had either normal or corrected-to-normal vision and were native speakers of Spanish.

Materials. A set of 128 disyllabic Spanish words five letters long was selected from the Spanish word pool (Alameda \& Cuetos, 1995) as a function of word frequency (low-frequency words vs. highfrequency words) and neighborhood size (low- $N$ words vs. high- $N$ words). One hundred and twenty-eight orthographically legal nonwords were constructed for the purposes of the lexical decision task. In order to maximize our chances of obtaining a facilitative effect of $N$ on low-frequency words, high- $N$ words tended to have more neighbors than did the nonwords. (As we said earlier, the effect of $N$ with Spanish words seems to be less robust than the reported effect of $N$ with English words; see, e.g., Carreiras et al., 1997b.) Half of the nonwords had been created by changing an interior letter from disyllabic Spanish words with five or six orthographic neighbors. The other half of the nonwords were constructed by combining two Spanish syllables and then checking that the constructed nonwords did not have any orthographic neighbors, while being orthographically legal in Spanish. The characteristics of the items used in the experiment are presented in Table 1. Word and nonword stimuli were counterbalanced across two experimental lists so that, if a letter string was presented in the limited viewing time condition in the first list, it would be presented in the unlimited viewing time condition in the second list. The materials are provided in the Appendix.

Design. For words, viewing time (limited or unlimited), word frequency (high frequency or low frequency), and neighborhood size (high $N$ or low $N$ ) were varied within subjects. For nonwords, viewing time (limited or unlimited) and neighborhood size (high $N$ or low $N$ ) were varied within subjects. Each participant was given a total of 256 experimental trials: 128 word trials and 128 nonword trials.

Procedure. The participants were tested in groups of 4-8 in a quiet room. Presentation of the stimuli and recording of RTs were controlled by Apple Macintosh Classic II microcomputers. The routines for controlling stimulus presentation and RT collection were obtained from Lane and Ashby (1987) and from Westall, Perkey, and Chute (1986), respectively. The stimuli were presented on the computer screen in 12-point Courier. At the beginning of each trial, the sequence " $><$ "was presented for $200 \mathrm{msec}$ on the center of the screen. After a 50-msec blank, the target stimulus was presented (always in lowercase). On half of the trials, the stimulus presentation duration was limited to $150 \mathrm{msec}$, and it was followed by a backward pattern mask of five number signs (\#\#\#\#), which remained on the screen until the participant responded (limited viewing time condition); on the other half of the trials, the target stimulus remained on the screen until the participant's response (unlimited viewing time condition). The participants were instructed to press one of two buttons on the keyboard to indicate whether the letter string was a Spanish word or not. The participants used their dominant hands to make the word response. This decision was to be made as rapidly and as accurately as possible. RTs were measured from the onset of the letter string until the participant's response. The intertrial inter- 
Table 1

Characteristics of the Stimuli in Experiments 1 and 2

\begin{tabular}{|c|c|c|c|c|c|c|}
\hline \multirow[b]{2}{*}{ Stimuli } & \multicolumn{2}{|c|}{ Word Frequency } & \multicolumn{2}{|c|}{$N$} & \multicolumn{2}{|c|}{$P$} \\
\hline & Mean & Range & Mean & Range & Mean & Range \\
\hline \multicolumn{7}{|l|}{ Words } \\
\hline High frequency, high $N$ & 102.0 & $26-515$ & 9.9 & $8-16$ & 3.7 & $2-5$ \\
\hline High frequency, low $N$ & 115.0 & $27-667$ & 0.5 & $0-1$ & 0.5 & $0-1$ \\
\hline Low frequency, high $N$ & 3.6 & $1-8$ & 9.3 & $8-15$ & 3.3 & $2-5$ \\
\hline High frequency, low $N$ & 3.7 & $1-9$ & 0.5 & $0-1$ & 0.5 & $0-1$ \\
\hline \multicolumn{7}{|l|}{ Nonwords } \\
\hline $\operatorname{High} N$ & - & - & 4.3 & $1-10$ & 2.0 & $1-4$ \\
\hline Low $N$ & - & - & 0 & $0-0$ & 0 & $0-0$ \\
\hline
\end{tabular}

val was set to $400 \mathrm{msec}$. Each participant received a different random order of stimuli. Each participant received a total of 24 practice trials (with the same manipulation as in the experimental trials) prior to the experimental phase. The session lasted approximately $15 \mathrm{~min}$.

\section{Results and Discussion}

Lexical decision latencies less than $250 \mathrm{msec}$ or greater than $1,500 \mathrm{msec}$ were excluded from the latency analyses (fewer than $0.5 \%$ for words and $0.4 \%$ for nonwords). Mean lexical decision latencies for correct responses and mean error rates were calculated across individuals and across items, and these means were submitted to separate analyses of variance (ANOVAs) for participants and items, respectively. For the word data, participant and item ANOVAs based on the participants' and items' response latencies and percentages of error were conducted with a 2 (word frequency: high or low) $\times 2$ (neighborhood size: high or low) $\times 2$ (viewing time: limited or unlimited $) \times$ 2 (list: List 1 or List 2) design. In this and subsequent analyses, the list factor was included as a dummy variable to extract the variance that was due to the error associated with the lists (Pollatsek \& Well, 1995). For the nonword data, participant and item ANOVAs based on the participants' and items' response latencies and percentages of error were conducted with a 2 (neighborhood size: high or low) $\times 2$ (viewing time: limited or unlimited) $\times 2$ (list: List 1 or List 2) design. The mean lexical decision latencies and error rates from the participant analysis are presented in Table 2. Unless otherwise noted, all significant effects have $p$ values less than the .05 level.

Word data. The ANOVAs on the latency data showed a significant effect of word frequency $\left[F_{1}(1,22)=75.24\right.$, $\left.M S_{\mathrm{e}}=2,504.9 ; F_{2}(1,120)=66.75, M S_{\mathrm{e}}=4,324.9\right]$ : Highfrequency words were responded to faster than lowfrequency words. The main effect of neighborhood size was not significant $\left[F_{1}(1,22)=2.27, M S_{\mathrm{e}}=1,049.6, p>\right.$ $\left..14 ; F_{2}(1,120)=1.51, M S_{\mathrm{e}}=4,324.9, p>.14\right]$. The interaction between word frequency and neighborhood size was significant $\left[F_{1}(1,22)=10.09, M S_{\mathrm{e}}=1,395.6\right.$; $\left.F_{2}(1,120)=5.78, M S_{\mathrm{e}}=4,324.9\right]$. This interaction reflected a facilitative effect of neighborhood size for lowfrequency words $\left[F_{1}(1,22)=9.76, M S_{\mathrm{e}}=1,435.8\right.$; $\left.F_{2}(1,120)=6.59, M S_{\mathrm{e}}=4,324.9\right]$ and a small, nonsignificant inhibitory effect of $N$ for high-frequency words $\left[F_{1}(1,22)=2.42, M S_{\mathrm{e}}=1,009.5, p>.13 ; F_{2}(1,120)<1\right.$, $\left.M S_{\mathrm{e}}=4,324.9\right]$. The other effects were not significant (all $p \mathrm{~s}>.10)$.

The ANOVAs on the error data showed a significant effect of word frequency $\left[F_{1}(1,22)=41.74, M S_{\mathrm{e}}=82.38\right.$; $\left.F_{2}(1,120)=39.66, M S_{\mathrm{e}}=115.60\right]$. The main effect of neighborhood size was marginally significant in the analysis by participants $\left[F_{1}(1,22)=3.37, M S_{\mathrm{e}}=47.31\right.$,

Table 2

Mean Lexical Decision Times (in Milliseconds) and Error Rates (Percentages of Errors, PE) for the Word and Nonword Targets in Experiment 1 (Yes/No Task)

\begin{tabular}{|c|c|c|c|c|c|c|}
\hline \multirow[b]{3}{*}{ Targets } & \multicolumn{6}{|c|}{ Viewing Time } \\
\hline & \multicolumn{2}{|c|}{ Limited } & \multicolumn{2}{|c|}{ Unlimited } & \multicolumn{2}{|c|}{ Unlimited - Limited } \\
\hline & $M$ & $\mathrm{PE}$ & $M$ & $\mathrm{PE}$ & $M$ & $\mathrm{PE}$ \\
\hline \multicolumn{7}{|l|}{ Words } \\
\hline High frequency, high $N$ & 606 & 3.4 & 602 & 4.4 & 24 & 1.0 \\
\hline High frequency, low $N$ & 587 & 2.3 & 601 & 3.9 & 14 & 1.6 \\
\hline Low frequency, high $N$ & 644 & 10.9 & 654 & 8.6 & 10 & 22.3 \\
\hline High frequency, low $N$ & 668 & 15.4 & 678 & 13.0 & 10 & 22.4 \\
\hline \multicolumn{7}{|l|}{ Nonwords } \\
\hline High $N$ & 733 & 13.5 & 731 & 9.5 & 22 & 24.0 \\
\hline Low $N$ & 686 & 4.3 & 684 & 3.3 & 22 & 21.0 \\
\hline
\end{tabular}


$\left.p<.08 ; F_{2}(1,120)=1.84, M S_{\mathrm{e}}=115.60, p>.15\right]$. The word frequency $\times$ neighborhood size interaction was significant in the analysis by participants $\left[F_{1}(1,22)=7.89\right.$, $\left.M S_{\mathrm{e}}=41.25\right]$, and it was marginally significant in the analysis by items $\left[F_{2}(1,120)=3.75, M S_{\mathrm{e}}=115.60, p<\right.$ .056]. This interaction reflected a facilitative effect of neighborhood size for low-frequency words $\left[F_{1}(1,22)=\right.$ $\left.5.06, M S_{\mathrm{e}}=78.87 ; F_{2}(1,120)=5.43, M S_{\mathrm{e}}=115.60\right]$, but not for high-frequency words $\left[F_{1}(1,22)=1.51, M S_{\mathrm{e}}=\right.$ $\left.9.69, p>.15 ; F_{2}(1,120)<1\right]$. The interaction between exposure duration and word frequency approached significance in the analysis by items $\left[F_{2}(1,120)=3.44, M S_{\mathrm{e}}=\right.$ $\left.61.78, p<.067 ; F_{1}(1,22)=2.37, M S_{\mathrm{e}}=67.4, p>.13\right]$, which reflected the fact that high-frequency words tended to provoke more errors in the limited viewing time condition than in the unlimited viewing time condition, whereas the reverse trend occurred for the low-frequency words. The other effects were not significant (all $p \mathrm{~s}>.15$ ).

Nonword data. The ANOVAs on the latency data showed a robust effect of neighborhood size $\left[F_{1}(1,22)=\right.$ $\left.78.55, M S_{\mathrm{e}}=686.4 ; F_{2}(1,120)=49.15, M S_{\mathrm{e}}=3,297.5\right]$ : High- $N$ nonwords were responded to more slowly than the low- $N$ nonwords. The other effects were not significant (all $F_{\mathrm{S}}<1$ ).

The ANOVAs on the error data also showed a significant effect of neighborhood size $\left[F_{1}(1,22)=52.36, M S_{\mathrm{e}}=\right.$ $\left.27.5 ; F_{2}(1,124)=33.25, M S_{\mathrm{e}}=115.57\right]$ : The participants committed more errors for high- $N$ nonwords than for low$N$ nonwords. The main effect of exposure duration was also significant $\left[F_{1}(1,22)=6.41, M S_{\mathrm{e}}=24.15 ; F_{2}(1,124)=\right.$ 6.04, $\left.M S_{\mathrm{e}}=68.31\right]$ : The participants committed more errors when the nonwords were presented for limited viewing time than when they were presented for unlimited viewing time. The interaction between these two factors was not significant (both $p$ s $>.10$ ).

The results of Experiment 1 showed the typical interaction between neighborhood size and word frequency: Low frequency showed a facilitative effect of neighborhood size, whereas high-frequency words showed a nonsignificant inhibitory trend (see, e.g., Carreiras, Perea, \& Grainger, 1997a, and Perea \& Rosa, 2002, for evidence of this interaction in Spanish). ${ }^{4}$ As usual, this facilitative effect of neighborhood size for low-frequency words was accompanied by an inhibitory effect of neighborhood size for nonwords. In addition, the magnitude of the word frequency effect was similar for unlimited and limited stimulus presentation exposures (see, also, Allen et al., 1992; Perea et al., 2002a). Interestingly, the lack of an interaction between word frequency and stimulus presentation duration seems to suggest that the $M$ criterion was not lowered in the limited viewing time condition.

Contrary to our expectations, the presence of brief and masked stimuli did not modify the neighborhood size effect for low-frequency words. Similarly, the effect of $N$ for nonwords was not significantly modified by exposure duration. The results of Experiment 1 may suggest that stimulus presentation duration does not seem to affect word processing. Nonetheless, we believe that it is important to replicate the experiment with a technique that uses only the word channel to make lexical decisions (the $M$ and the $\Sigma$ criteria are operative, whereas the $T$ criterion is not). Specifically, Experiment 2 was a go/no-go replication of Experiment 1.

\section{EXPERIMENT 2 Go/No-Go Lexical Decision Task}

\section{Method}

Participants. Twenty-four psychology students from the University of València took part in the experiment for course credit. All of them had either normal or corrected-to-normal vision and were native speakers of Spanish. None of them had participated in the previous experiment.

Design and Materials. The design and materials were the same as those in Experiment 1.

Procedure. The procedure was the same as that in Experiment 1, except that the participants were instructed to press a button on the keyboard with their dominant hands if the letter string was a legitimate Spanish word and to refrain from responding if the letter string was not a word. The stimulus item (or the pattern mask, in the limited viewing time condition) remained on the computer screen until the participant responded or until $2 \mathrm{sec}$ had elapsed.

\section{Results and Discussion}

Lexical decision latencies less than $250 \mathrm{msec}$ or greater than $1,500 \mathrm{msec}$ were excluded from the latency analyses (fewer than $0.6 \%$ ). Mean lexical decision latencies for correct responses and mean error rates were calculated

Table 3

Mean Lexical Decision Times (in Milliseconds) and Error Rates (Percentages of Errors, PE) for the Word and Nonword Targets in Experiment 2 (Go/No-Go Task)

\begin{tabular}{|c|c|c|c|c|c|c|}
\hline \multirow[b]{3}{*}{ Targets } & \multicolumn{6}{|c|}{ Viewing Time } \\
\hline & \multicolumn{2}{|c|}{ Limited } & \multicolumn{2}{|c|}{ Unlimited } & \multicolumn{2}{|c|}{ Unlimited - Limited } \\
\hline & $M$ & $\mathrm{PE}$ & $M$ & $\mathrm{PE}$ & $M$ & $\mathrm{PE}$ \\
\hline \multicolumn{7}{|l|}{ Words } \\
\hline High frequency, high $N$ & 577 & 0.5 & 572 & 0.0 & -5 & -0.5 \\
\hline High frequency, low $N$ & 563 & 0.3 & 564 & 0.0 & 1 & -0.3 \\
\hline Low frequency, high $N$ & 632 & 6.8 & 673 & 3.4 & 41 & -3.4 \\
\hline High frequency, low $N$ & 682 & 7.6 & 683 & 0.5 & 1 & -7.1 \\
\hline \multicolumn{7}{|l|}{ Nonwords } \\
\hline $\operatorname{High} N$ & - & 11.2 & - & 5.3 & - & -5.9 \\
\hline Low $N$ & - & 3.1 & - & 1.3 & - & -1.8 \\
\hline
\end{tabular}


across individuals and across items, and these means were submitted to separate ANOVAs for participants and items, respectively. The mean lexical decision latencies and percentages of errors from the participant analysis are presented in Table 3.

Word data. The ANOVAs on the latency data showed a significant effect of word frequency $\left[F_{1}(1,22)=134.64\right.$, $\left.M S_{\mathrm{e}}=4,153.4 ; F_{2}(1,120)=101.24, M S_{\mathrm{e}}=6,350.1\right]$ : Highfrequency words were responded to faster than lowfrequency words. The main effect of neighborhood size was not significant $\left[F_{1}(1,22)=2.97, M S_{\mathrm{e}}=1,397.7\right.$; $\left.F_{2}(1,120)<1\right]$. The interaction between word frequency and neighborhood size was significant in the analysis by participants $\left[F_{1}(1,22)=24.91, M S_{\mathrm{e}}=828.9 ; F_{2}(1,120)=\right.$ $\left.3.48, M S_{\mathrm{e}}=6,350.1, p=.0647\right]$, which reflected a facilitative effect of neighborhood size for low-frequency words $\left[F_{1}(1,22)=15.27, M S_{\mathrm{e}}=1,418.6 ; F_{2}(1,120)=3.88\right.$, $\left.M S_{\mathrm{e}}=6,350.1, p=.068\right]$ and a nonsignificant inhibitory trend for high-frequency words $\left[F_{1}(1,22)=3.89, M S_{\mathrm{e}}=\right.$ $\left.808.0, p=.068 ; F_{2}(1,120)=0.64, M S_{\mathrm{e}}=6350.1\right]$. The interaction between word frequency and exposure duration was significant $\left[F_{1}(1,22)=6.69, M S_{\mathrm{e}}=940.9 ; F_{2}(1,120)=\right.$ $\left.7.43, M S_{\mathrm{e}}=1,088.8\right]$, which reflected a significant effect of stimulus-presentation duration for low-frequency words $\left[F_{1}(1,22)=4.76, M S_{\mathrm{e}}=2,216.1 ; F_{2}(1,120)=12.58\right.$, $M S_{\mathrm{e}}=1,088.8$ ], but not for high-frequency words (both $\left.F_{\mathrm{S}}<1\right)$. The interaction between neighborhood size and exposure duration approached significance $\left[F_{1}(1,22)=\right.$ $3.47, M S_{\mathrm{e}}=943.9, p=.075 ; F_{2}(1,120)=3.70, M S_{\mathrm{e}}=$ $1,088.8, p=.056]$. Finally, the interaction between word frequency, neighborhood size, and exposure duration was significant $\left[F_{1}(1,22)=6.12, M S_{\mathrm{e}}=1,081.0 ; F_{2}(1,120)=\right.$ $\left.7.37, M S_{\mathrm{e}}=1,088.8\right]$. This three-way interaction reflected the fact that the effect of exposure duration occurred in the low-frequency high- $N$ condition ( 41 msec: 673 vs. $632 \mathrm{msec}$ under unmasked and masked conditions), but not in the other conditions ( $1 \mathrm{msec}$ for the high-frequency high- $N$ condition, $-5 \mathrm{msec}$ for the high-frequency high- $N$ condition, and $1 \mathrm{msec}$ for the low-frequency low- $N$ condition).

The ANOVAs on the error data showed a significant effect of word frequency $\left[F_{1}(1,22)=24.65, M S_{\mathrm{e}}=37.05\right.$; $\left.F_{2}(1,120)=14.76, M S_{\mathrm{e}}=82.48\right]$. Neither the main effect of neighborhood size nor the neighborhood size $\times$ word frequency interaction was significant (all $p \mathrm{~s}>.15$ ). The main effect of exposure duration was significant $\left[F_{1}(1,22)=\right.$ $\left.17.55, M S_{\mathrm{e}}=21.44 ; F_{2}(1,120)=24.14, M S_{\mathrm{e}}=20.78\right]$. The interaction between exposure duration and word frequency was significant $\left[F_{1}(1,22)=13.96, M S_{\mathrm{e}}=19.96\right.$; $\left.F_{2}(1,120)=17.87, M S_{\mathrm{e}}=20.78\right]$, which reflected the fact that the effect of exposure duration affected the lowfrequency words more than it did the high-frequency words. With respect to the other interactions, only the threeway interaction between the three main factors approached significance [in the analysis by items; $F_{2}(1,120)=2.94$, $\left.M S_{\mathrm{e}}=20.78, p=.089 ; F_{1}(1,22)=1.60, M S_{\mathrm{e}}=20.78, p>.15\right]$.

Nonword data. The ANOVAs on the error data showed a significant effect of neighborhood size $\left[F_{1}(1,22)=38.57\right.$, $\left.M S_{\mathrm{e}}=22.81 ; F_{2}(1,124)=28.79, M S_{\mathrm{e}}=83.26\right]$ : The par- ticipants committed more errors for high- $N$ nonwords than for low- $N$ nonwords. The main effect of exposure duration was also significant $\left[F_{1}(1,22)=19.39, M S_{\mathrm{e}}=18.26\right.$; $\left.F_{2}(1,124)=21.10, M S_{\mathrm{e}}=21.10\right]$ : The participants committed more errors when the nonwords were presented for unlimited viewing time than when they were presented for limited viewing time. Finally, unlike in Experiment 1, the interaction between neighborhood size and exposure duration was significant $\left[F_{1}(1,22)=4.39, M S_{\mathrm{e}}=22.26\right.$; $\left.F_{2}(1,124)=6.00, M S_{\mathrm{e}}=46.29\right]$ : There was a robust effect of exposure duration for the high- $N$ nonwords $\left[F_{1}(1,22)=\right.$ $\left.13.43, M S_{\mathrm{e}}=30.68 ; F_{2}(1,124)=24.80, M S_{\mathrm{e}}=46.29\right]$, whereas this effect was much weaker for the low- $N$ nonwords $\left[F_{1}(1,22)=4.05, M S_{\mathrm{e}}=9.84, p=.056 ; F_{2}(1,124)=\right.$ $\left.2.30, M S_{\mathrm{e}}=46.29, p>.13\right]$.

Overall, the present experiment replicated the basic findings of Experiment 1 (i.e., a facilitative effect of $N$ for low-frequency words and an inhibitory effect of $N$ for nonwords). Not surprisingly, the percentage of word errors in the present experiment was rather low $(0.2 \%$ and $4.6 \%$ for high- and low-frequency words, respectively; see also Hino \& Lupker, 1998, 2000; Perea et al., 2002b). ${ }^{5}$ But more important, the neighborhood size effect for lowfrequency words was much larger in the limited viewing time condition than in the unlimited viewing time condition (50 vs. $10 \mathrm{msec}$, respectively). This large neighborhood size effect was essentially due to the fact that there was a strong effect of stimulus presentation duration in the low-frequency high- $N$ condition (632 and $673 \mathrm{msec}$ for the limited and unlimited viewing time conditions, respectively), but not in the other conditions. Likewise, the neighborhood size effect for nonwords was greater under limited viewing time than under unlimited viewing time (errors at $8.9 \%$ vs. $4.0 \%$ ).

\section{GENERAL DISCUSSION}

The main findings of the present experiments can be summarized as follows: (1) Stimulus presentation duration interacted with neighborhood size in the go/no-go lexical decision task (the neighborhood size effect being greater with brief/masked presentations than with unlimited viewing time presentations), but not in the yes/no task; (2) the neighborhoodsize effect occurred for low-frequency, but not for high-frequency, words; (3) the word frequency effect was greater in the go/no-go task than in the yes/no task. Taken together, these findings have important implications for models of visual-word recognition.

\section{Brief Presentations, Familiarity, and the Lexical Decision Task}

As in prior research, the present experiments showed a facilitative effect of $N$ for low-frequency words (but not for high-frequency words) and an inhibitory effect of $N$ for nonwords (see Andrews, 1997). These results are compatible with those models that assume that lexical decisions can be made via global lexical activation $(\Sigma$ decision criterion; e.g., the MROM, the DRC model, and the 


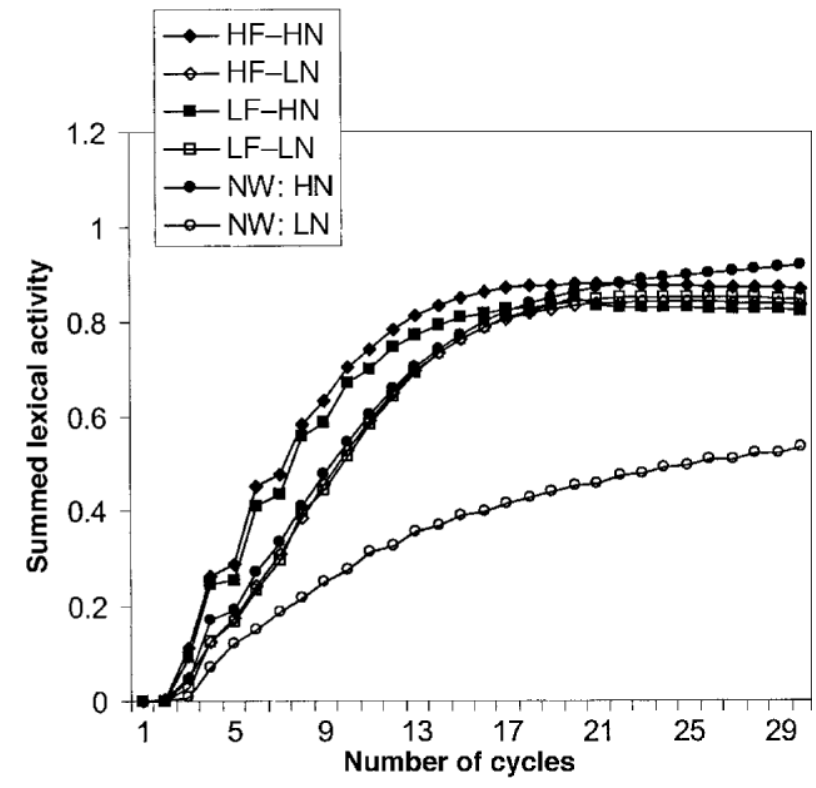

Figure 1. Simulation results with the interactive activation model, showing summed activation levels over all word units for the word and nonword (NW) trials. HF, high frequency; LF, low frequency; $\mathrm{HN}$, high $N$; LN, low $N$.

AV model), but not with the original IA model: Word identification latencies in the IA model are predicted to be longer for high- $N$ words that for low- $N$ words, as determined by the number of cycles that it took until the activation at a word node reached a threshold (or $M$ criterion) of 0.70: 20.1 versus 18.8 cycles for low-frequency high- $N$ words and for low-frequency low- $N$ words, respectively (see Grainger \& Jacobs, 1996; Perea \& Rosa, 2000). To conduct the simulations, the IA model was implemented with a Spanish lexicon of 3,885 five-letter words in a way that was identical to the implementation made by Jacobs and Grainger (1992; see also Perea \& Rosa, 2000). The parameters used were the ones given as defaults by Rumelhart and McClelland (1982), except that the letterto-word excitation parameter was set to .06 (see Grainger $\&$ Jacobs, 1996, for a similar adjustment for five-letter words).

If lexical decision responses are based on the summed lexical activity, the relevant activation function would be given in Figure 1. All the trials tested in the present experiments were presented to the model, and the summed activation over all lexical units for the stimulus items in an IA model was recorded (see Figure 1). It is clear that early in processing, high- $N$ words enjoy an advantage over nonwords in summed lexical activity, which may favor the use of incomplete processing of the stimuli to make the lexical decision response (i.e., the $\Sigma$ criterion for word responses) and, thereby, a facilitative effect of $N$ for word stimuli. The lack of a facilitative effect of $N$ for highfrequency words is probably due to the fact that familiar words typically reach the $M$ criterion more rapidly than they reach the $\Sigma$ criterion (Grainger \& Jacobs, 1996; see, also, Carreiras et al., 1997a). Note that in order to make a correct response, the use of a criterion based on summed lexical activity does not discriminate between low- $N$ words and high- $N$ nonwords, which implies that low- $N$ words should be responded to on the basis of the $M$ criterion. Finally, the low lexical activity of the low- $N$ nonwords (relative to the high- $N$ nonwords) can be used to set a shorter deadline for $n o$ responses (i.e., the $T$ criterion), and it is responsible for the inhibitory effect of $N$ for nonwords. Thus, the basic pattern of neighborhood effects can be captured by the MROM. The question now is why the effect of neighborhood size for low-frequency words was modulated by exposure duration in one of the varieties of the lexical decision task (the go/no-go task), but not in the other (the yes/no task). ${ }^{6}$

Let us analyze first the neighborhood size effect (for low-frequency words) in the yes/no task. The neighborhood size effect for low-frequency words was virtually the same (24 msec) in the limited and the unlimited viewing time conditions. In the MROM, this result would suggest that the participants relied on the $\Sigma$ criterion to the same degree both in the limited and in the unlimited viewing time conditions. Consistent with this explanation, the effect of exposure duration on RTs was rather small: a nonsignificant 9.5-msec effect, with faster responding in the limited viewing time condition. (Bear in mind that increased use of the $\Sigma$ criterion in the limited viewing time condition would imply faster responding.) Likewise, the neighborhood size effect for nonwords did not differ as a function of exposure duration.

In contrast, the neighborhood size effect for lowfrequency words with the go/no-go task was much larger in the limited viewing time condition than in the unlimited viewing time condition (50 vs. $10 \mathrm{msec}$ ). As we said earlier, the only way the MROM can explain this facilitative effect of neighborhood size for words is by increasing the number of trials in which the $\Sigma$ criterion is used. This would necessarily be accompanied by faster responding. This is exactly what happened with the low-frequency high- $N$ words in the limited viewing time condition (Experiment 2). Consistent with this finding, the participants made more nonword errors (i.e., yes responses to nonwords) in the limited than in the unlimited viewing time condition, especially for the (wordlike) high- $N$ nonwords. In other words, the participants seem to have increased the use of the $\Sigma$ criterion in the limited viewing time condition. Alternatively, one might argue that, under limited viewing time, the participants tended to misidentify the target item as the highest frequency neighbor, which would have provoked "fast" responses for those items (see Coltheart et al., 2001; Pollatsek et al., 1999). (Of course, in order to make sure that the participant was retrieving a higher frequency neighbor instead of the target word, he or she would need to say aloud the retrieved item after making the lexical decision. Nonetheless, the fact that the 
participants made a number of yes responses to nonwords suggests that, on a number of trials, the participants just retrieved the wrong item.)

In sum, the use of a brief exposure duration increased the magnitude of the neighborhood size effect for both words and nonwords, at least in one variety of the lexical decision task (the go/no-go lexical decision task), which suggests once again that the effect of $N$ is partly due to a decision-biasing effect. These results are consistent with the view that lexical decisions to word stimuli may be made on the basis of summed lexical activation (or some other form of stimulus familiarity), rather than on the basis of unique word identification. Unfortunately, it is not easy to explain why the two modalities of the lexical decision task showed different patterns of neighborhood size effects as a function of exposure presentation duration: Yes responses in the two tasks apparently should be driven by the same mechanism (i.e., either the $\Sigma$ or the $M$ criterion). Thus, the MROM model has some difficulty explaining why the larger effect of $N$ in the limited viewing condition than in the unlimited viewing condition occurs with the go/no-go variant of the lexical decision task, but not with the yes/no modality. (The same reasoning also applies to the DRC model and the AV model.)

It is worth noting that Grainger and Jacobs (1996) indicated that the feature-to-letter excitation parameter could be reduced with very brief (and masked) presentations of the target word. However, in the limited viewing condition, stimuli were presented for $150 \mathrm{msec}$, and thus it is likely that processing of the stimulus was guided by a nonsensory representation of the input. Furthermore, this modification in the feature-to-letter excitation parameter would imply that word accumulation evidence would be slower, and then responses to words would have been slower. Finally, it is not clear to us how these changes in the parameters could affect differentially the yes/no and the go/no-go lexical decision tasks. For instance, in the limited viewing time condition, participants seem to increase the use of summed lexical activity to arrive at a yes decision in the go/no-go task, but not in the yes/no task. The current version of the MROM would predict a similar increase in the use of the $\Sigma$ criterion in the two tasks.

One possible (admittedly post hoc) explanation for the present findings is in terms of the different processing demands in the two tasks (see, e.g., Grice \& Reed, 1992, for differential effects of target redundancy with choice and go/no-go tasks in a letter classification experiment). The go/no-go task requires decisions to only one type of items (i.e., it needs only the word channel), and it appears to require fewer processing demands than does the yes/no task (Perea et al., 2002b; Yelland, 1993). For instance, Yelland found that the go/no-go task, but not the yes/no task, can be applied to experiments with special populations (e.g., children). Interestingly, previous research has found that the pattern of masked form-priming effects differs as a function of task demands. In a series of masked priming experiments with the lexical decision task, Forster and Veres (1998) found that, when the task was difficult (when the nonword distractors closely resembled a worde.g., umbrolla), nonword primes (but not masked word primes) yielded a reliable masked form-priming effect (e.g., junction-function or bunction-function; the priming effects were 37 and $8 \mathrm{msec}$, respectively). When the task was easy (i.e., the nonword distractors did not resemble any particular words-e.g., ambrolla), Forster and Veres found reliable masked form-priming effects for both nonword and word primes (the priming effects were 34 and $32 \mathrm{msec}$, respectively). In an activation-based model (e.g., the MROM), this can be accomplished by reducing the parameters responsible for lateral inhibition between words when the task is not difficult (i.e., the go/no-go task): In this way, both masked nonword and word stimuli tend to fall into attractors for (activated) words rather easily. This would explain the large neighborhood size effect for lowfrequency high- $N$ words under limited viewing time condition. In contrast, when the task requires more processing demands (i.e., the yes/no task), masked nonword stimuli are more likely to fall into attractors for (activated) words than are masked word stimuli. Not surprisingly, if the word-to-word inhibition parameter is reduced to .16 in the IA model (the default value in the model is .21), high$N$ words enjoy some extra advantage over nonwords in summed lexical activation (see Figure 2), which implies that participants can make use of the $\Sigma$ criterion for lowfrequency high- $N$ words (but not for low-frequency low- $N$ words) without the risk of making an error.

Thus, changes in display duration might influence the weighting of information that participants use to make

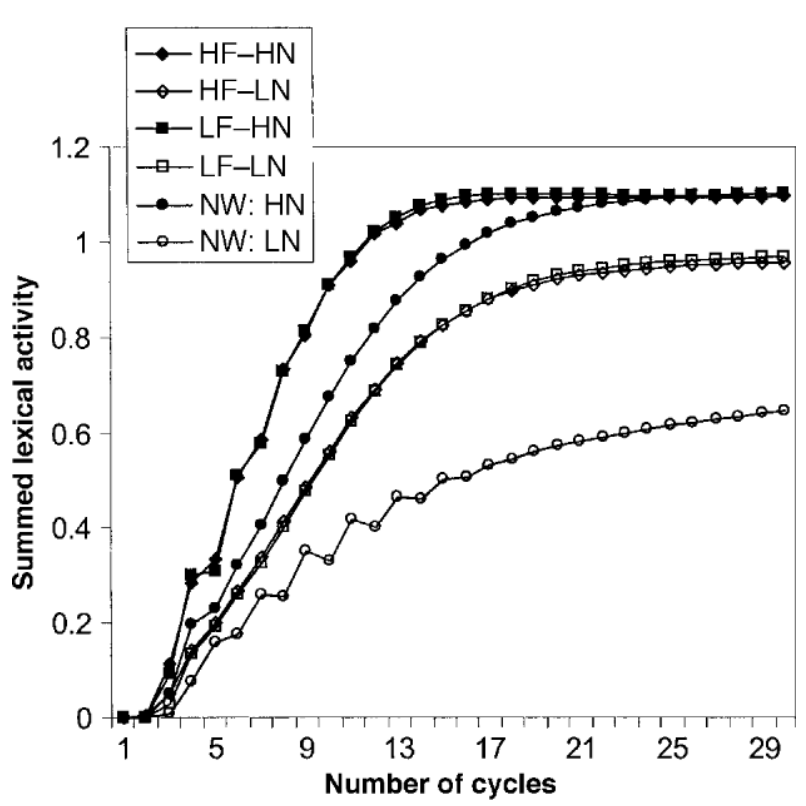

Figure 2. Simulation results with the interactive activation model, showing summed activation levels over all word units for the word and nonword (NW) trials (the word-to-word inhibition parameter was reduced to.16; the default value in the model is .21). HF, high frequency; LF, low frequency; HN, high $N ; \mathrm{LN}$, low $N$. 
their decisions. In order to examine the differential effects that may occur with the yes/no and the go/no-go lexical decision tasks, current research in our lab is devoted to modeling these two tasks in terms of a diffusion/randomwalk model (Gómez, Perea, \& Ratcliff, 2002). Results from additional experimentation and modeling work suggest that the difference between the yes/no and the go/nogo lexical decision tasks may be due not to the lack of a response criterion for no responses in the go/no-go task (i.e., participants may use an implicit $n o$ decision that does not require an overt response), but to the use of different criterion settings for yes responses (Gómez et al., 2002). Therefore, it is possible that the type of information available may be different under limited and unlimited viewing conditions, and this may mean that the decision process (yes/no vs. go/no-go) is different under these two conditions.

Finally, it should be noted that $N$ could have not only a task-specific component, but also a genuine facilitative effect on word processing (e.g., Andrews, 1997; Grainger, Carreiras, \& Perea, 2000; Sears, Lupker, \& Hino, 1999; Zagar \& Mathey, 2000). For instance, Grainger et al. (2000) found a facilitative effect of $N$ with the luminance increment paradigm (a speeded perceptual identification task; i.e., the $\Sigma$ criterion is not operative), whereas these same items had yielded an inhibitory effect of $N$ with a progressive demasking task. Similarly, Sears, Lupker, and Hino (1999) found a facilitative effect of $N$ in a semantic categorization task; in this task, the $\Sigma$ criterion is not operative either. These facilitative effects of $N$ probably reflect top-down reinforcement of sublexical processing from whole-word representations (see Andrews, 1989, 1992, 1997; Grainger et al., 2000; Mathey \& Zagar, 2000; Sears, Lupker, \& Hino, 1999), and this reverberatory process may well depend on the processing demands of the task (Grainger et al., 2000) and on the way orthographic neighbors are distributed across letter position (Mathey \& Zagar, 2000; Zagar \& Mathey, 2000). This is clearly an issue that deserves further research.

\section{The Word Frequency Effect in the Go/No-Go and the Yes/No Tasks}

As usual, the participants in the go/no-go task made fewer errors to word stimuli than did participants in the yes/no task [ $2.4 \%$ vs. $7.7 \%$, respectively; $F_{1}(1,44)=26.87$; $F_{2}(1,120)=75.53$; see also Hino \& Lupker, 1998, 2000; Perea et al., 1998, 2002b]. However, unlike previous research in our lab (e.g., Perea et al., 1998; Perea et al., 2002b), the participants were not significantly faster in the go/nogo task than in the yes/no task [618 vs. $630 \mathrm{msec}$, respectively; $\left.F_{1}(1,44)<1 ; F_{2}(1,120)=14.39\right]$. The lack of a reliable effect in the latency data could be due to the fact that the participants used a more lenient criterion for yes responses in the yes/no task: The participants made more nonword errors (i.e., yes responses to nonword stimuli) in the yes/no task than in the go/no-go task $[7.7 \%$ vs. $5.2 \%$, respectively; $\left.F_{1}(1,44)=4.85 ; F_{2}(1,124)=15.08\right]$. (In addition, it should be noted that the two experiments were
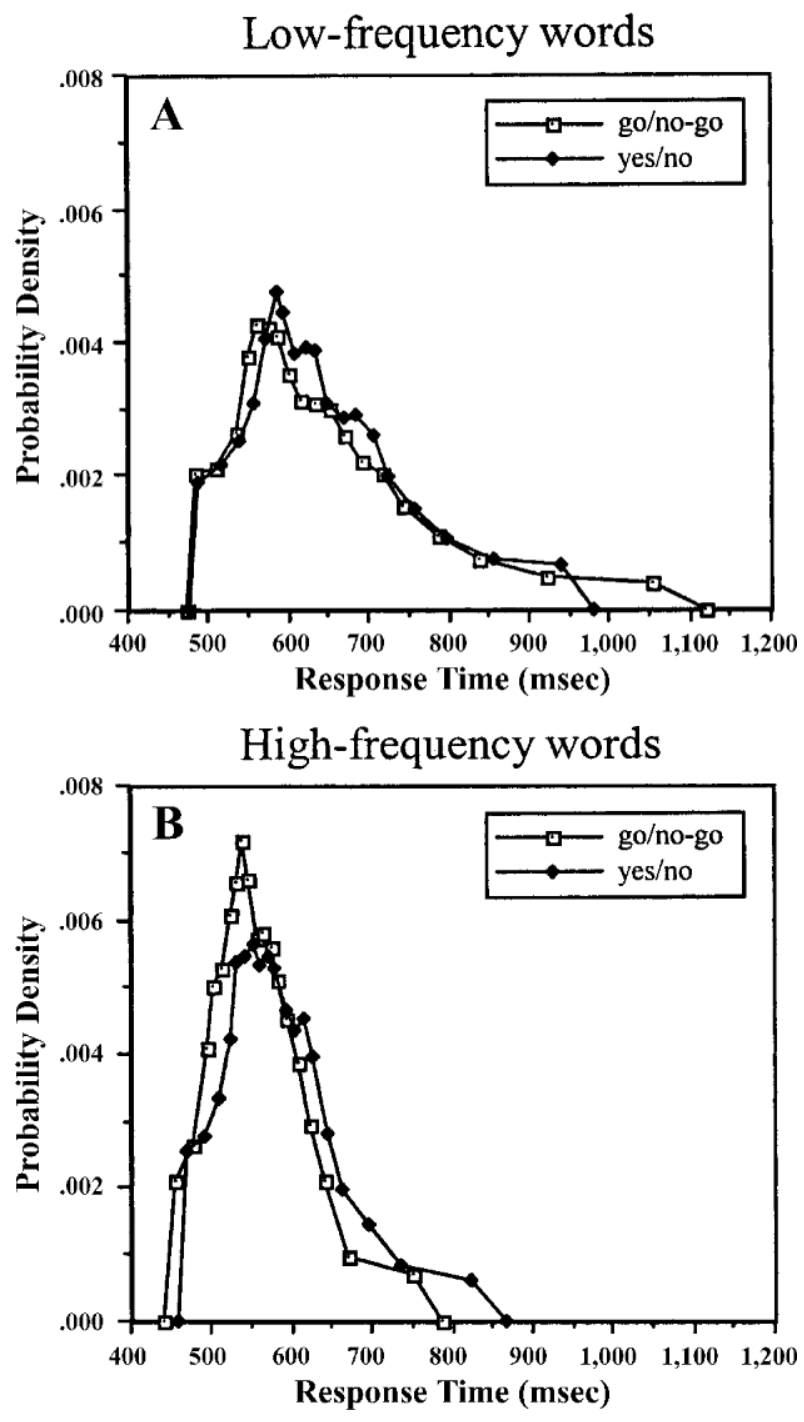

Figure 3. Group reaction time distributions for low- and highfrequency words in the go/no-go task and the yes/no task.

run in two consecutive semesters, so the participants were not randomly assigned to each level of task.)

More important, the magnitude of the word frequency effect was larger with the go/no-go task than with the yes/no task (98.5 vs. $62 \mathrm{msec}$, respectively). This finding is not entirely novel, since Hino and Lupker (1998) reported a 163 - and a 108 -msec word frequency effect for the go/no-go and the yes/no tasks, respectively. (The magnitude of the word frequency effect was 121 and $96 \mathrm{msec}$ for the go/no-go and the yes/no tasks in the Hino \& Lupker, 2000, experiments.) However, in previous experiments in our lab, we found a similar word frequency effect for the go/no-go task and the yes/no task (74 vs. $63 \mathrm{msec}$, respectively, in Perea et al.'s, 1998, report, and 129 vs. $123 \mathrm{msec}$ in Perea et al.'s, 2002b, report). Although one could argue that additivity has no special significance when the 
Table 4

Mean Response Time Standard Deviations (in Milliseconds) for the Word Targets in Experiments 1 and 2

\begin{tabular}{lrrrr}
\hline & \multicolumn{4}{c}{ Neighborhood Category } \\
\cline { 2 - 5 } Condition & HF-HN & HF-LN & LF-HN & LF-LN \\
\hline Yes/no task & & & & \\
$\quad$ Unlimited viewing & 105.5 & 100.5 & 132.4 & 127.2 \\
$\quad$ Limited viewing & 98.3 & 91.8 & 123.6 & 119.8 \\
Go/no-go task & & & & \\
$\quad$ Unlimited viewing & 99.4 & 82.6 & 163.0 & 144.9 \\
$\quad$ Limited viewing & 79.7 & 79.9 & 146.2 & 146.2 \\
\hline
\end{tabular}

Note-HF-HN, high frequency, high $N$; HF-LN, high frequency, low $N$; LN-HN, low frequency, high $N$; LF-LN, low frequency, low $N$.

word/nonword error rates in the two tasks are quite different, we believe that it is important to examine this apparent discrepancy carefully.

Hino and Lupker $(1998,2000)$ indicated that when an unfamiliar low-frequency word is encountered, participants might make the wrong answer in the yes/no task and those trials would end up counting as errors, not contributing to the mean latency for that condition. In contrast, in the go/no-go task, the participant could eventually realize that the unfamiliar item is a word, producing a slow response and, thereby, a larger word frequency effect. Hino and Lupker did not provide any additional statistical analyses (e.g., an analysis of the shape of the RT distribution) in support of their explanation, however. To test this hypothesis, we proceeded to compare the shapes of the RT distributions. Specifically, we computed the $5 \%$ quantiles based on all the correct RTs for each participant and word frequency condition (high frequency vs. low frequency). Then, each quantile was averaged across participants to give group quantiles (i.e., Vincent averages). (These average distributions have approximately the same shape as component distributions; see Ratcliff, 1979.) The empirical distributions are given in Figure 1. If participants make a higher number of slow responses to the low-frequency words in the go/no-go task than in the yes/no task, the right tail of the RT distribution should be longer for the go/no-go task. Indeed, the empirical RT distributions with $5 \%$ quantiles based on all the correct RTs for the low-frequency words show that the RT distribution for the go/nogo task has a longer tail than the RT distribution for the yes/no task (see Figure 3A). Not surprisingly, this trend did not appear for the high-frequency words (see Figure 3B). Thus, these analyses give empirical support to Hino and Lupker's hypothesis. (The MROM might also predict a longer tail with low-frequency words for the go/no-go task. This would be the direct result of the presence of slow responses in the go/no-go task that could have been no responses in the yes/no task.)

We should note that in Perea et al.'s (1998; Perea et al., 2002b) experiments, the RT distributions for low-frequency and for very low frequency words in the go/no-go task did not have a longer tail than the corresponding RT distributions in the yes/no task. The reason for this discrepancy is not obvious. One possibility is that the partic- ipants were using different criterion settings in the two tasks. In the positive reports of a larger word frequency effect with the go/no-go task (i.e., the present experiments; see, also, Hino \& Lupker, 1998, 2000), the percentage of nonword errors was consistently higher for the yes/no task. In contrast, in the two experiments that obtained additive effects of word frequency and task (Perea et al., 1998; Perea et al., 2002b), the percentage of nonword errors was remarkably similar in the two tasks. Another possibility is that all the nonwords in Perea et al.'s (1998; Perea et al., 2002b) experiments were six letters long and tended to have very few (if any) neighbors (e.g., a mean of 1.2 word neighbors in Perea et al.'s, 2002b, study). In contrast, in the present experiment, the items were shorter (five-letter items), and half of the nonwords had been created by changing one letter from mediumdensity words. As a result, many of the words in the present study had lower levels of lexical activity than did many of the nonwords, which may have produced different processing demands, relative to Perea et al.'s (1998; Perea et al., 2002b) experiments.

Finally, let us examine briefly whether the go/no-go lexical decision task produces less noisy data than does the yes/no task, as was suggested by Gordon (1983) and Peressotti and Grainger (1995). If we use error variance (as measured by $M S_{\mathrm{e}} \mathrm{s}$ ) as an estimate of the sensitivity of the procedure, the variability tends to be somehow higher with the go/no task than with the yes/no task (see the Results sections for Experiments 1 and 2; see, also, Hino \& Lupker, 1998, 2000; Perea et al., 2002b). Nonetheless, there is the possibility that task differences might be more directly related to within-subjects (trial by trial) variability than the $M S_{\mathrm{e}}$ s. Given the relatively large number of trials per cell, this source of variability may not translate into large $M S_{\mathrm{e}}$ differences. For that reason, we analyzed how the tasks differed with respect to the within-cell standard deviation averaged across participants (see Table 4). In the high-frequency words, variability indexed in this way was lower in the go/no-go task $[99.0 \mathrm{vs} .85 .4 \mathrm{msec}$ in the yes/no and the go/no-go tasks, respectively; $F(1,44)=$ $3.22, p=.080]$, which is consistent with Gordon's claim. However, the reverse effect occurred for low-frequency words [125.7 vs. $150.7 \mathrm{msec}$ in the yes/no and the go/nogo tasks, respectively; $F(1,44)=7.91, p<.008$ ]. Nonetheless, the reduction in variance for low-frequency words in the yes/no task is probably related to the fact that some of the variability corresponding to the word stimuli is removed by the false negative errors in the yes/no task (see above). Further research is necessary to examine the (potential) reduction of variance in the go/no-go lexical decision task, at least for high-frequency words.

\section{Conclusions}

To summarize, this paper has clearly shown that the neighborhood size effect in the lexical decision task can be modulated by a decision-biasing factor, especially in the go/no-go version of the task. In addition, the present results give empirical support to Hino and Lupker's (1998, 
2000) claim relative to the differential processing demands that may occur in the yes/no and the go/no-go tasks. More research is needed to fully examine the similarities and differences between these two seemingly similar tasks. Finally, we believe that an analysis of the shape of RT distributions should receive more attention for those investigators interested in RTs (for some recent examples, see Andrews \& Heathcote, 2001; Balota \& Spieler, 1999; Ratcliff, Gómez, \& McKoon, 2002).

\section{REFERENCES}

Alameda, J. R., \& Cuetos, F. (1995). Diccionario de frecuencia de las unidades lingüísticas del castellano [Dictionary of word frequency in Spanish]. Oviedo: Servicio de publicaciones de la Universidad de Oviedo.

Allen, P. A., McNeal, M., \& Kvak, D. (1992). Perhaps the lexicon is coded as a function of word frequency. Journal of Memory \& Language, 31, 826-844.

ANDREWS, S. (1989). Frequency and neighborhoodeffects on lexical access: Activation or search? Journal of Experimental Psychology: Learning, Memory, \& Cognition, 15, 802-814.

ANDREWS, S. (1992). Frequency and neighborhoodeffects on lexical access: Lexical similarity or orthographic redundancy? Journal of Experimental Psychology: Learning, Memory, \& Cognition, 18, 234-254.

ANDREws, S. (1996). Lexical retrieval and selection processes: Effects of transposed-letter confusability. Journal of Memory \& Language, 35, 775-800.

ANDREws, S. (1997). The effects of orthographic similarity on lexical retrieval: Resolving neighborhood conflicts. Psychonomic Bulletin \& Review, 4, 439-461.

Andrews, S., Content, A., \& Peereman, R. (2000, November). Crosslanguage differences in the effects of orthographic neighbors. Paper presented at the 41st Annual Meeting of the Psychonomic Society, New Orleans.

Andrews, S., \& Heathcote, A. (2001). Distinguishing common and task-specific processes in word recognition: A matter of some moment? Journal of Experimental Psychology: Learning, Memory, \& Cognition, 27, 514-544.

Balota, D. A., \& Spieler, D. H. (1999). Word frequency, repetition, and lexicality effects in word recognition. Journal of Experimental Psychology: General, 128, 32-55.

Carreiras, M., Perea, M., \& Grainger, J. (1997a, November). Blocking by frequency and neighborhood density. Paper presented at the 38th Annual Meeting of the Psychonomic Society, Philadelphia.

Carreiras, M., Perea, M., \& Grainger, J. (1997b). Effects of orthographic neighborhood in visual word recognition: Cross-task comparisons. Journal of Experimental Psychology: Learning, Memory, \& Cognition, 23, 857-871.

Coltheart, M., Davelaar, E., Jonasson, J. F., \& Besner, D. (1977). Access to the internal lexicon. In S. Dornic (Ed.), Attention and performance VI (pp. 535-555). Hillsdale, NJ: Erlbaum.

Coltheart, M., Rastle, K., Perry, C., Langdon, R, \& Ziegler, J. (2001). DRC: A dual route cascaded model of visual word recognition and reading aloud. Psychological Review, 108, 204-256.

Davis, C., CAst les, A., \& IAKovidis, E. (1998). Masked homophone and pseudohomophone priming in children and adults. Language \& Cognitive Processes, 13, 625-651.

Forster, K. I. (1976). Accessing the mental lexicon. In R. J. Wales \& E. W. Walker (Eds.), New approaches to languagemechanisms (pp. 257287). Amsterdam: North-Holland.

ForSTER, K. I. (2000). The potential for experimenter bias effects in word recognition experiments. Memory \& Cognition, 28, 1109-1115.

ForsteR, K. I., \& SHEN, D. (1996). No enemies in the neighborhood: Absence of inhibitory effects in lexical decision and categorization. Journal of Experimental Psychology: Learning, Memory, \& Cognition, 3, 696-713.
Forster, K. I., \& Veres, C. (1998). The prime lexicality effect: Formpriming as a function of prime awareness, lexical status, and discrimination difficulty. Journal of Experimental Psychology: Learning, Memory, \& Cognition, 24, 498-514.

Gibbs, P., \& VAn Orden, G. C. (1998). Pathway selection's utility for control of word recognition. Journal of Experimental Psychology: Human Perception \& Performance, 24, 1162-1187.

Gómez, P., Perea, M., \& Ratcliff, R. (2002, July). A model of the "go/no-go" lexical decision task. Paper presented at the 35th Annual Meeting of the Society for Mathematical Psychology, Oxford, $\mathrm{OH}$.

Gordon, B. (1983). Lexical access and lexical decision: Mechanisms of frequency sensitivity. Journal of Verbal Learning \& Verbal Behavior, 22, 24-44.

Gordon, B., \& Caramazza, A. (1982). Lexical decision for open- and closed-class words: Failure to replicate differential frequency sensitivity. Brain \& Language, 15, 143-160.

Grainger, J. (1992). Orthographic neighborhoods and visual word recognition. In R. Frost \& L. Katz (Eds.), Orthography, phonology, morphology, and meaning (pp. 131-146). Elsevier: Amsterdam.

Grainger, J., Carreiras, M., \& Perea, M. (2000). A new technique for visual word recognition research: The luminance increment paradigm. Current Psychology Letters, 1, 107-116.

Grainger, J., \& JACOBS, A. M. (1996). Orthographic processing in visual word recognition: A multiple read-out model. Psychological Review, 103, 518-565.

Grainger, J., O'Regan, J. K., Jacobs, A. M., \& Segui, J. (1989). On the role of competing word units in visual word recognition: The neighborhood frequency effect. Perception \& Psychophysics, 45, 189-195.

Grainger, J., O'Regan, J. K., Jacobs, A. M., \& Segui, J. (1992). Neighborhood frequency effects and letter visibility in visual word recognition. Perception \& Psychophysics, 51, 49-56.

Grainger, J., \& Segui, J. (1990). Neighborhood frequency effects in visual word recognition: A comparison of lexical decision and masked identification latencies. Perception \& Psychophysics, 47, 191-198.

Grice, G. R., \& Reed, J. M. (1992). What makes targets redundant? Perception \& Psychophysics, 51, 437-442.

Hino, Y., \& LupKeR, S. J. (1998). The effects of word frequency for Japanese Kana and Kanji words in naming and lexical decision: Can the dual-route model save the lexical-selection account? Journal of Experimental Psychology: Human Perception \& Performance, 24, 1431-1453.

Hino, Y., \& LuPKer, S. J. (2000). The effects of word frequency and spelling-to-sound regularity in naming with and without lexical decision. Journal of Experimental Psychology: Human Perception \& Performance, 26, 166-183.

Huntsman, L. A., \& Lima, S. D. (1996). Orthographic neighborhood structure and lexical access. Journal of P sycholinguistic Research, 25 , 417-429.

JACOBS, A. M., \& GRAInger, J. (1992). Testing a semistochastic variant of the interactive activation model in different word recognition experiments. Journal of Experimental Psychology: Human Perception \& Performance, 18, 1174-1188.

Jacobs, A. M., Rey, A., Ziegler, J. C., \& Grainger, J. (1998). MROMP-p: An interactive activation multiple readout model of orthographic and phonological processes in visual word recognition. In J. Grainger \& A. M. Jacobs (Eds.), Localist connectionist approaches to human cognition (pp. 147-188). Mahwah, NJ: Erlbaum.

Jared, D., McRae, K., \& Seidenberg, M. S. (1990). The basis of consistency effects in word naming. Journal of Memory \& Language, 29, 687-715.

Lane, D. M., \& Ashby, B. (1987). PsychLib: A library of machine language routines for controlling psychology experiments on the Apple Macintosh computer. Behavior Research Methods, Instruments, \& Computers, 19, 246-248.

Mathey, S., \& Zagar, D. (2000). The neighborhood distribution effect in visual word recognition: Words with single and twin neighbors. Journal of Experimental Psychology: Human Perception \& Performance, 26, 184-205.

McClelland, J. L., \& Rumelhart, D. E. (1981). An interactive acti- 
vation model of context effects in letter perception: Pt. 1. An account of basic findings. Psychological Review, 88, 375-407.

PaAp, K. R., \& Johansen, L. S. (1994). The case of the vanishing frequency effect: A retest of the verification model. Journal of Experimental Psychology: Human Perception \& Performance, 20, 1129 1157.

Paap, K. R., Newsome, S. L., McDonald, J. E., \& Schvaneveldt, R. W. (1982). An activation-verification model for letter and word recognition: The word superiority effect. Psychological Review, 89, 573594.

Peereman, R., \& Content, A. (1995). Neighborhood size effect in naming: Lexical activation or sublexical correspondences? Journal of Experimental Psychology: Learning, Memory, \& Cognition, 21, 409-421.

Perea, M., \& Carreiras, M. (1996). Efectos de frecuencia silábica y vecindad ortográfica en la pronunciación de palabras y pseudopalabras [Effects of syllable frequency and orthographic neighborhood in the naming of words and pseudowords]. Psicológica, 17, 425-440.

Perea, M., \& Carreiras, M. (1998). Effects of syllable frequency and neighborhood syllable frequency in visual word recognition. Journal of Experimental Psychology: Human Perception \& Performance, 24, $1-11$.

Perea, M., Fernández, L., \& Carreiras, M. (1998, December). Efectos secuenciales en la tarea de decisión léxica [Sequential effects in the lexical decision task]. Paper presented at the II Conference of the Spanish Experimental Psychology Society, Granada.

Perea, M., \& Pollatsek, A. (1998). The effects of neighborhood frequency in reading and lexical decision. Journal of Experimental Psychology: Human Perception \& Performance, 24, 767-779.

Perea, M., \& Rosa, E. (2000). Repetition and form priming interact with neighborhood density at a brief stimulus onset asynchrony. Psychonomic Bulletin \& Review, 3, 668-677.

Perea, M., \& Rosa, E. (2002). Does “whole-word shape" play a role in visual word recognition? Perception \& Psychophysics, 64, 785794.

Perea, M., \& Rosa, E. (in press). Los efectos de facilitación semántica con las tareas de decisión léxica sí-no y sólo-sí [The effects of semantic priming with the yes/no and the go/no-go lexical decision task]. Psicothema.

Perea, M., Rosa, E., \& Gómez, C. (2002a). The frequency effect for pseudowords in the lexical decision task. Manuscript submitted for publication.

Perea, M., Rosa, E., \& Gómez, C. (2002b). Is the go/no-go lexical decision task an alternative to the yes/no lexical decision task? Memory \& Cognition, 30, 34-45.

Peressotti, F., \& Grainger, J. (1995). Letter-position coding in random consonant arrays. Perception \& Psychophysics, 57, 875-890.

Plaut, D. C., McClelland, J. L., Seidenberg, M. S., \& Patterson, K. (1996). Understanding normal and impaired word reading: Computational principles. Psychological Review, 103, 56-115.

Pollatsek, A., Perea, M., \& Binder, K. (1999). The effects of neighborhood size in reading and lexical decision. Journal of Experimental Psychology: Human Perception \& Performance, 25, 1142-1158.

Pollatsek, A., \& Well, A. (1995). On the use of counterbalanced designs in cognitive research: A suggestion for a better and more powerful analysis. Journal of Experimental Psychology: Learning, Memory, \& Cognition, 21, 785-794.

RATCLIFF, R. (1979). Group reaction time distributions and an analysis of distribution statistics. Psychological Bulletin, 86, 446-461.

Ratcliff, R., Gómez, P., \& McKoon, G. (2002). A diffusion model account of the lexical decision task. Manuscript submitted for publication.

Rumelhart, D. E., \& McClelland, J. L. (1982). An interactive activation model of context effects in letter perception: Pt. 2 . The contextual enhancement effect and some tests and extensions of the model. Psychological Review, 89, 60-94.

Sears, C. R., Hino, Y., \& LuPKer, S. J. (1995). Neighborhood frequency and neighborhood size effects in visual word recognition.
Journal of Experimental Psychology: Human Perception \& Performance, 21, 876-900.

Sears, C. R., Hino, Y., \& LuPKer, S. J. (1999). Orthographic neighbourhood effects in parallel distributed processing models. Canadian Journal of Experimental Psychology, 53, 220-229.

Sears, C. R., LuPKer, S. J., \& Hino, Y. (1999). Orthographic neighborhood effects in perceptual identification and semantic categorization tasks: A test of the multiple read-out model. Perception \& Psychophysics, 61, 1537-1554.

Seidenberg, M. S., \& McClelland, J. L. (1989). A distributed, developmental model of word recognition and naming. Psychological Review, 96, 523-568.

Treiman, R., Mullennix, J., Bijeljac-Babic, R., \& RichmondWelty, E. D. (1995). The special role of rimes in the description, use, and acquisition of English orthography. Journal of Experimental Psychology: General, 124, 107-136.

Westall, R, Perkey, M. N., \& Chute, D. L. (1986). Accurate millisecond timing on Apple's Macintosh using Drexel MilliTimer. Behavior Research Methods, Instruments, \& Computers, 18, 307-311.

YELLAND, G. (1993, November). Is there a placefor phonologicalprocesses in reading development? Paper presented at the 9th Australian Language and Speech Conference, Sydney.

ZAGAR, D., \& MATHEY, S. (2000). When WORDS with higher frequency neighbours become words with no higher frequency neighbors (or how to undress the neighbourhood frequency effect). In A. Kennedy, R. Radach, D. Heller, \& J. Pynte (Eds.), Reading as a perceptual process (pp. 23-46). Oxford: Elsevier.

Ziegler, J. C., \& Perry, C. (1998). No more problems in Coltheart's neighborhood: Resolving neighborhood conflicts in the lexical decision task. Cognition, 68, 53-62.

\section{NOTES}

1. We should note that Pollatsek et al.(1999) and Mathey and Zagar (2000; see, also, Zagar \& Mathey, 2000) showed that the IA model can predict a facilitative effect of $N$ under specific circumstances. (In the present study, the IA model predicts an inhibitory effect of $N$, at least with the default parameters; see the General Discussion section.)

2. We will not discuss parallel distributed processing models (e.g., Plaut, McClelland, Seidenberg, \& Patterson, 1996; Seidenberg \& McClelland, 1989), since computational implementation of these models deals only with monosyllabic items. All the items in the present experiment were disyllabic. In any case, it may be of interest to note that these models can readily capture the facilitative effect of $N$ on lexical decisions to words, but not the inhibitory effect of neighborhood frequency (see Sears, Hino, \& Lupker, 1999).

3. The mean RT reported in Experiment 2 was actually $438 \mathrm{msec}$. However, it seems very likely that the clock started at mask onset rather than at stimulus onset (see Paap \& Johansen, 1994, for a similar observation). For that reason, we used $598 \mathrm{msec}(438+160 \mathrm{msec})$ in the text.

4. Although one could argue that the difference in $N$ (fewer than two neighbors vs. eight or more neighbors) is qualitative rather than quantitative, we would like to note that there is evidence in Spanish that syllabic neighbors (i.e., words that share a syllable with the target word, especially the first syllable) are activated in the process of visual-word recognition (see Perea \& Carreiras, 1998). All the stimuli were disyllabic, so it is likely that even lexical hermits had some competitors in the set of candidates.

5 . The percentage of errors in the low-frequency high- $N$ condition with unlimited viewing time was essentially caused by two words: terso (smooth) and cinto (belt; $50 \%$ and 25\% errors, respectively). (In Spanish, the most direct translation of belt is cinturón.)

6 . It is worth noting that the combined analysis of Experiments 1 and 2 showed that both the neighborhood size $\times$ task $\times$ exposure duration interaction and the word frequency $\times$ task $\times$ exposure duration interaction were statistically significant $\left[F_{1}(1,44)=5.12, F_{2}(1,120)=5.02\right.$, and $F_{1}(1,44)=6.98, F_{2}(1,120)=5.45$, respectively $]$. 
APPENDIX

Word and Nonword Targets in the Experiments

\section{High-Frequency High- $\boldsymbol{N}$ Words}

patio, barro, marca, corto, grado, santo, banda, carga, media, razón, barra, forma, monte, cuero, trato, salto, lleno, calle, plano, costa, gesto, gusto, suelo, mente, solar, corte, marco, barco, cajón, mando, moral, carta.

\section{High-Frequency Low- $\boldsymbol{N}$ Words}

vital, motor, radio, pluma, golpe, grave, nariz, error, feliz, joven, mujer, favor, virus, negro, mitad, honor, total, suave, ritmo, civil, orden, fácil, rigor, miedo, salud, carne, reloj, genio, señor, árbol, dulce, hotel.

\section{Low-Frequency High- $N$ Words}

dólar, muela, parra, batín, panal, regar, tazón, tarro, facha, cabra, suela, socio, resta, suero, pasto, tinto, tallo, gorro, pitar, garra, valla, hacha, menta, traca, barca, palmo, gramo, cinto, terso, talón, matón, zorro.

\section{Low-Frequency Low- $N$ Words}

suizo, matiz, tarot, puñal, reuma, furor, himno, rosal, bozal, potro, naipe, belga, tecla, esquí, audaz, cisne, misil, sidra, rapaz, nevar, miope, flúor, rifle, tifus, boina, molde, tigre, mamut, deuda, cromo, fósil, sesgo.

\section{High- $N$ Nonwords}

chajo, frato, turto, lebio, jupio, bapón, sapro, cuspa, gribo, mitar, fobra, bacho, munco, maclo, vatón, derar, teron, refar, verpe, trofo, treno, cuena, llafe, gorpo, ribio, cieto, fetia, cuche, sibre, honto, pliza, guala, huemo, pleto, tiste, churo, hirto, flejo, bacle, pulto, cieve, lobro, juedo, binco, linza, pifon, brima, reifa, prefa, lumar, caula, murzo, lamin, rembo, caral, nuego, pubre, fulda, gados, patre, culmo, silpo, golgo, buzar.

\section{Low- $N$ Nonwords}

astol, asbia, siraz, zumel, pisme, nifla, yaril, leror, lufla, beimo, elcer, gibil, boico, dogir, jasfa, ulcre, bonfa, rapre, elpel, bunaz, elbir, birno, fopiz, vaifo, riaro, caive, horer, boñir, cobis, asmer, hiñor, fidor, ailir, fesor, bemiz, arcil, nagla, zosor, cravi, osper, asfín, febir, arche, algra, notra, indel, eslaz, ornor, sugal, rufil, soqui, clilo, dubol, auvia, cibir, cijor, anfra, laitu, cedaz, femel, nobor, bojor, tufal, oidín. 